\title{
La muerte de Lucrecia y la insistencia de la pintura
}

\section{The Death of Lucretia and the Insistence of Painting}

\author{
Miriam Moreno AguiRre \\ Universidad Complutense de Madrid \\ miriam.morenoagui@gmail.com
}

Recibido: 23 de noviembre de 2010

Aceptado: 24 de noviembre de 2010

\section{Resumen}

El cuadro de Rosales La muerte de Lucrecia inquieta a Ramón Gaya. Su reflexión en torno a esta obra abre una serie de interrogantes acerca de la experiencia estética contemporánea que tiene que ver con la leyenda del suicidio de Lucrecia en tanto que metáfora de la muerte de los grandes creadores que, como en el caso dramático de Rosales, han perdido la fuerza y las energías para llevar a cabo la ingente tarea de luchar contra unos límites que, lejos de ampliarse, quedan convertidos en clichés a toda velocidad. La búsqueda de una definición de pintura con la ayuda de Deleuze pone en tela de juicio el desalojo de la pintura en tanto que práctica supuestamente anacrónica en el contexto de un paradigma de dominio de lo digital.

Palabras clave: Pintura, fuerza, trascendencia, analógico, digital.

\begin{abstract}
Rosales' painting The Death of Lucretia disturbed Ramón Gaya. His thoughts on that work open up a series of questions about contemporary aesthetic experience that concerns the legend of Lucretia's suicide as a metaphor of the death of great artists. As in the dramatic case of Rosales, these latter have lost their strength and energy to carry out the daunting task of struggling against limits that, far from expanding, are promptly turned into clichés. The search for a definition of painting
\end{abstract}


with the help of Deleuze puts into question the eviction of painting as an anachronistic practice in the context of a paradigm of the digital domain.

Keywords: Painting, strength, transcendence, analogical, digital.

Gaya pintó en 1996 un homenaje a Eduardo Rosales protagonizado por La muerte de Lucrecia, una de las resonancias de la pintura gayesca que encontramos además en un óleo de 1988 titulado El gran desnudo de Rosales y el brazo de su Lucrecia, así como en un dibujo de ese magnífico cuerpo desvanecido, fechado en 1968, y en un gouache de 2001. Podríamos decir, por tanto, que el pintor murciano nos ha dejado a lo largo de su trayectoria pictórica, al menos, cuatro piezas en torno a La muerte de Lucrecia. ¿Pero qué significado late en esa insistencia?

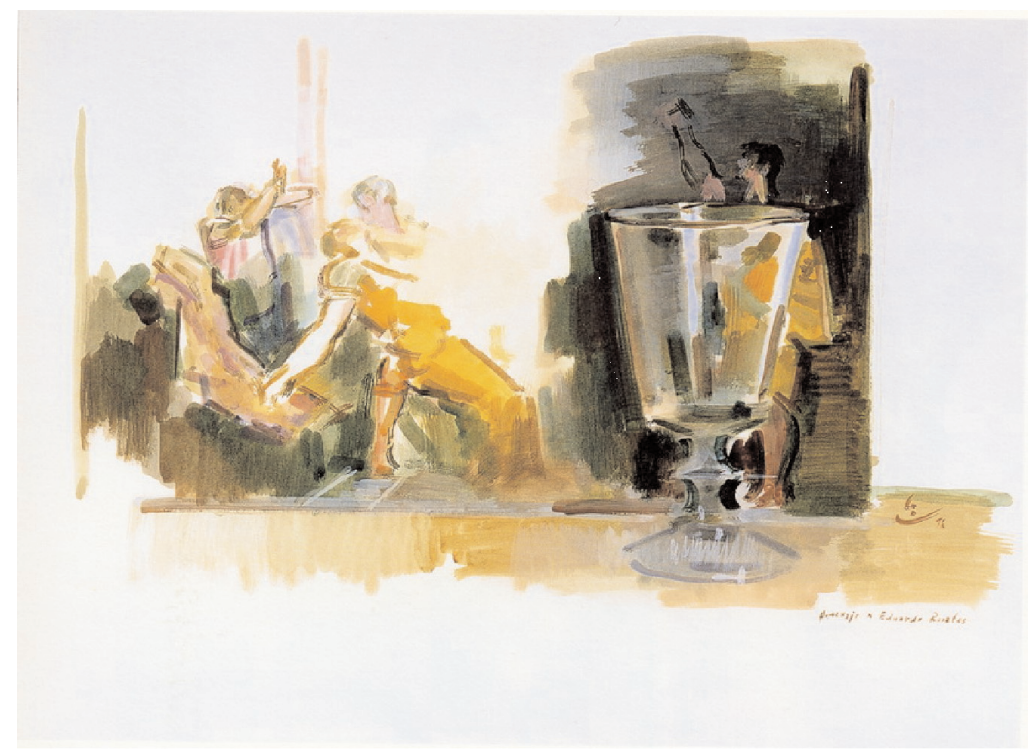

La pintura europea se hace eco de la leyenda de la romana Lucrecia violada por Tarquinio y el juramento de venganza de Bruto que ocasiona la caída de la monarquía y la proclamación de la República en la antigua Roma. La narración nos ha llegado en los textos de Tito Livio, Ovidio y Virgilio, ${ }^{1}$ pero es a partir del Renacimiento cuando la trágica muerte de Lucrecia transita por las obras de Botticelli, Alberto Durero, Tiziano, Guido Reni, Rafael, Tintoretto, Veronese, Luca Giordano y Tiepolo, entre muchos otros. Unas pinturas que quizá no pretendían únicamente mostrar la virtud de esta mujer que se suicida tras haber perdido su honor, sino que más bien satisfacían con el pretexto de la leyenda, la demanda de imáge-

\footnotetext{
${ }_{1}^{1}$ Las referencias están tomadas de documentos disponibles en: http://www.pintorrosales.com/ y en http://www.museodelprado.es/coleccion/galeria-on-line/galeria-on-line/obra/la-muerte-de-lucrecia/
} 
nes eróticas de desnudo femenino. La poesía y la música recrean igualmente este relato de la historia romana. Son ejemplos el poema que escribió William Shakespeare titulado La violación de Lucrecia y la cantata Lucrecia que compuso Friedrich Händel. En 1946 Benjamin Britten estrena la que muchos consideran su mejor ópera, The Rape of Lucretia.

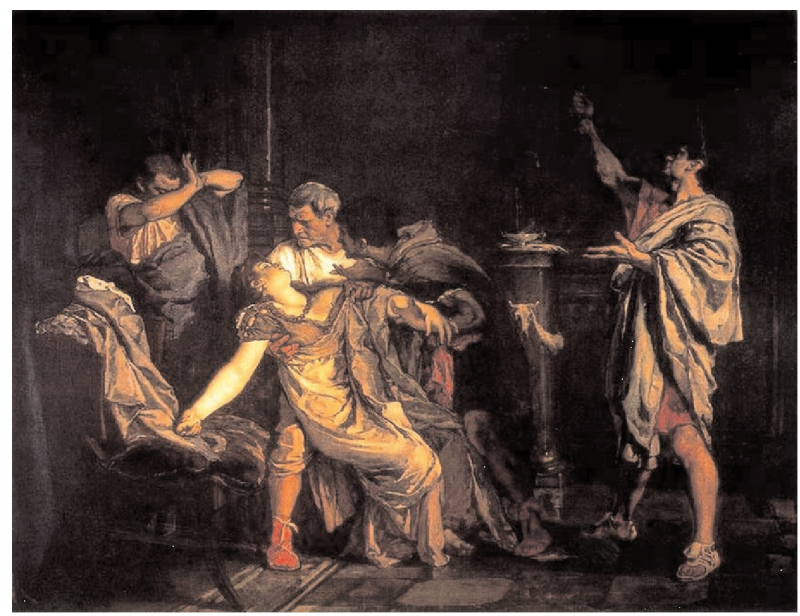

Durante el siglo XIX el asunto siguió siendo un tema apreciado por los pintores neoclásicos y románticos. Eduardo Rosales lo rescata poniendo el acento en su carga sentimental. Se trata de un óleo sobre lienzo de gran tamaño, que el pintor madrileño tarda cinco años en pintar. En esta estampa típicamente romántica y de gran realismo a la vez, todo es movimiento. Los cinco personajes del drama nos dan la impresión de densidad y corporeidad: Valerio que cubre su rostro horrorizado, Lucrecia desvanecida en brazos de su padre Spurio Lucrecio que está junto a su esposo Colatino y, algo más retirada, la figura de Bruto que, con el puñal ensangrentado en la mano, no puede contener su grito de furia. En el centro del cuadro, como protagonista absoluta, está Lucrecia sobre cuyo brazo, de extraordinaria belleza pictórica, pesa la sombra de la muerte. Contemplando esta pintura colosal cabría pensar que Lucrecia es ofrecida en tanto que víctima sacrificial al acontecimiento histórico de la República romana.

A propósito de esta pintura cuenta Juan Ramón Jiménez en Españoles de tres mundos lo siguiente:

Eduardo Rosales no tenía estudio, y tal ministro amante de las artes le había cedido un salón alto del Congreso. En el salón no había más que el cuadro, Rosales y el frío. Me dijo que, cada vez que daba una pincelada grande, tenía que sentarse ¿dónde? a toser; como si la fuerza, el volumen, el peso que dejaba al hermoso brazo de Lucrecia por ejemplo, se las arrancara del pecho. ${ }^{2}$

2 Jiménez, J.R, Españoles de tres mundos, Madrid, Aguilar, 1969, pp. 83 y 84. 
Al aludir Juan Ramón en este texto a la grave enfermedad pulmonar que estaba socavando lentamente la vida del pintor nos sugiere que Rosales, al pintar La muerte de Lucrecia, se había ido quedando exhausto y sin fuerzas ya para luchar contra esa otra fuerza enemiga, la de la muerte. Y puede que así fuera. Lo cierto es que este cuadro, aunque obtuvo una primera medalla en la Exposición Nacional de Bellas Artes de 1871, dio pie a numerosas críticas ocasionadas por la modernidad de su ejecución de pincelada ancha y rápida. Críticas que incomodaron al maestro hasta el extremo de retirar el lienzo a su casa, donde lo guardó hasta su muerte en 1873.

Al leer este relato de Juan Ramón Jiménez da la impresión de que la verdadera protagonista del cuadro no es Lucrecia, sino que lo es la muerte en general y en particular la muerte de la Pintura, de la pintura de tema. Así nos lo dice Ramón Gaya en un texto fechado en México en 1953: «En Rosales he visto siempre al último gran pintor español...antiguo, de una antigüedad que no es propiamente de estilo ni de tiempo, sino de casta. Es el último estertor de una pintura grande, grandiosa, generosa; después, claro está, vamos a encontrarnos con Nonell y con Solana, los dos muy verdaderos, aunque un tanto... a la desesperada. Rosales pertenece aún a esa casta mayor, es cierto que no puede con ella, pues su casta es antigua, sí, pero él, Rosales, es ya un moderno, sus fuerzas son modernas, pequeñas, pero luchará con tanta bravura que ha de lograr pintar un cuadro que lo emparenta con Tintoretto La muerte de Lucrecia. En ese cuadro entrecortado hay, como se sabe -por lo menos como sabe muy bien J. R.-, un brazo caído, moribundo, que me parece lleno de significación; es un brazo cargado ya de muerte y sensual todavía, opulento, lívido, que se rinde, que entrega el alma; nunca me pareció, sin embargo, que perteneciese por entero a la figura de Lucrecia, sino que se trataba más bien del brazo mismo de la Pintura; una pintura que, malherida por el siglo XIX, no tenía más remedio que abdicar, y que abdicaba, eso sí, con gloria, en una especie de agonía triunfante.» ${ }^{3}$

Gaya capta el drama del pintor moderno que ya no tiene fuerza para llevar a cabo la descomunal tarea de la pintura de tema. Ya no puede seguir sosteniendo esa lucha. Entonces el brazo rendido de la Pintura con mayúsculas, malherida, exhala el último estertor en una agonía triunfante. ¿Se refería Gaya a la muerte de la Pintura en el mismo sentido que hoy se habla de la muerte del Arte? ¿O se trata de un final que anuncia un nuevo comienzo?

Da la impresión de que es mayoritaria la opinión que se complace en certificar la defunción del arte como si se tratara de un hecho cierto, ineludible y necesario. Muerte de un Arte con mayúsculas que ya no cabe en el nuevo paradigma cultural, pues se diría que no tiene otra opción que la de abdicar para dejar paso a un sinfín de actividades artísticas con minúscula o penetraciones efímeras que no admiten ninguna pretensión de trascendencia, ni de transfiguración de lo cotidiano, pero que

3 Gaya, R., Obra completa, Valencia, Pre-Textos, p. 171. 
sustentan en cambio una fe ciega en el mercado. Más allá de conjeturas un tanto triviales ¿en qué medida estos pronósticos luctuosos tienen que ver con la transformación de nuestra experiencia y la llamada revolución digital? Permítaseme lanzar aquí esta pregunta únicamente como propuesta para pensar en torno a la experiencia estética contemporánea.

Cuando asistimos al nacimiento de nuevos modos de celebración de la novedad como un valor en sí en el mundo de las nuevas tecnologías, la tercera parte de la población mundial ya es "internauta". Las nuevas tecnologías son indudablemente herramientas asombrosas que aumentan nuestras capacidades de autogestión, de conocer el mundo y de comunicarnos. Han modificado nuestros hábitos y determinan nuestra experiencia. Sin embargo, fascinados con las ventajas que aporta la velocidad digital, al concentrar toda nuestra energía en los ojos y los dedos durante una cantidad considerable de tiempo, no reparamos en los inconvenientes de la lógica de obsolescencia programada, motor de la economía moderna que impone el movimiento circular de comprar, tirar, comprar. ${ }^{4}$ Tampoco parecen preocuparnos algunos indicios del empobrecimiento de nuestra experiencia que han sacado a la luz estudios recientes, donde se demuestra que nuestra entrega diaria a multitareas en el ordenador que exige horas frente a la pantalla saltando de una página de internet a otra, reduce nuestra capacidad de concentración. 5 Podríamos decir que en nuestra distracción no nos damos cuenta de que estamos distraídos, porque en la aceleración contemporánea de optimización del cambio continuo no cabe la atención extrema, una de las condiciones necesarias para crear, como decía Simone Weil. 6

¿Tendrá que ver esta nueva circunstancia con el llamado fin del arte? Ahora bien, parece ser que muchos pintores se hacen programadores de multimedios digitales y se suman a un mundo que ofrece nuevas posibilidades en el tratamiento de la imagen. Por lo tanto no podemos hablar de muerte del arte, sino más bien de la constatación de que la pintura ha perdido su papel primordial en el campo de las artes plásticas. De modo que quizá cuando hablamos de la muerte del arte estamos hablando, en realidad, de la muerte de la pintura. Pero, antes de darla por muerta y entonar las consabidas letanías fúnebres, deberíamos preguntarnos qué entendemos por pintura, en qué consiste el acto de pintar.

Gilles Deleuze en Francis Bacon. Lógica de la sensación, dice que la pintura es una insistencia. La pintura es una presencia que tiene que ver con la resonancia de las sensaciones. La sensación es lo que se transmite directamente evitando el rodeo

\footnotetext{
4 Documento disponible en http://www.eleconomista.es/economia/noticias/2727817/01/11/Victimasde-la-obsolescencia-programada-motor-de-la-economia-moderna.html

5 Carr, N., Un mundo distraído (entrevista de Bárbara Celis, publicada el 29 de enero de 2011 en El País, Babelia, pp. 5 a 7).

6 S. Weil, La gravedad y la gracia, traducción Jesús Pendás, Benito y Alejandro del Río Hermann, Madrid, Caparrós Heditores, 1994, p. 125.
} 
o el tedio de una historia que contar. Así la lógica de la sensación sería una lógica de los sentidos que, en palabras de Cezanne, no es ni racional, ni cerebral. ${ }^{7}$ En la sensación la figura actúa directamente sobre el sistema nervioso que es también carne. En la sensación están tanto sujeto y objeto como un ser-en-mundo.

En su comentario de la entrevista con David Sylvester, L'art de l'impossible, éd. Skira, Deleuze destaca que Bacon invoca dos ideas recogidas de Malraux para distinguir la pintura antigua de la pintura moderna en su relación con la figuración o la ilustración. Por una parte, la foto ha cargado con la función ilustrativa y documental, de modo que la pintura moderna no tiene que cubrir esta función que todavía pertenecía a la antigua. Por otra, la pintura antigua estaba aún condicionada por ciertas "posibilidades religiosas" que le daban un cierto sentido pictórico a la figuración, mientras que la pintura moderna es un juego ateo. Sin embargo Deleuze discute que estas ideas sean adecuadas. En su opinión fotografía y pintura se hacen la competencia puesto que la función de la fotografía no tiene por qué limitarse únicamente a representar. En cuanto al vínculo pictórico con el sentimiento religioso, tampoco le parece convincente que la función figurativa estuviera santificada por la fe. Un contraejemplo sería todo el arte gótico que tiende a la abstracción geométrica, tal como lo señala Worringer. Deleuze cree más bien que el sentimiento religioso hace posible la liberación de las figuras de su función figurativa, como ocurre por ejemplo en El entierro del Conde de Orgaz del Greco en el que las figuras se enderezan o se doblan, o se contorsionan, liberadas de toda figuración porque no tienen nada que representar o que narrar, sino que tienen que ver con sensaciones celestes o infernales. No se puede decir que la pintura religiosa sustentara la figuración en la pintura antigua, más bien al contrario, hacía posible la liberación de las figuras. Tampoco es plausible decir que la renuncia a la figuración sea más fácil para la pintura moderna, ni hay que caer en el error de suponer que el pintor trabaja sobre una superficie blanca y virgen, porque lo cierto es que cuando el pintor se propone iniciar su obra la superficie ya está investida virtualmente de toda clase de clichés con los que tendrá que romper. Deleuze dice que el problema de la pintura moderna es que está asediada por las fotos, está asediada por los clichés que se instalan en el lienzo. Lo que ocurre es que la pintura huye de la fotografía que pretende reinar sobre la vista.

Bacon tiene su manera particular de huir de la fotografía que no es superando la figuración hacia la abstracción, sino hacia la figura. Toma en consideración el cuerpo como material de la Figura, pero el cuerpo en cuanto a carne (chair) y en cuanto a pieza de carne (viande). Así pues su pintura se muestra en primer lugar como carnal. Carne como material corpóreo como si su pintura reclamara piedad para la pieza de carne, de tal modo que se puede decir que hay un devenir animal en la pin-

7 G. Deleuze, Francis Bacon, Lógica de la sensación, Madrid, Arena libros, 2009, p. 49. 
tura de Bacon que tiene que ver con una serie de trazos que constituyen una zona de indiscernibilidad, de indecidibilidad entre el hombre y el animal. No es el animal como forma, sino el animal como trazo. El hombre deviene animal, pero el animal deviene al mismo tiempo espíritu del hombre. Se trata de hallar el hecho común entre el hombre y el animal. De llegar hasta el "animal de fondo", como diría JRJ. En el devenir animal entra en juego la fascinación por el animal que muere como si de una tauromaquia latente se tratara. Bacon busca el fondo o unidad rítmica de los sentidos que sólo se puede descubrir superando el organismo y más allá del organismo está lo que Artaud denominó como cuerpo sin órganos, que es plena carne, emoción vital. Es el hecho intensivo del cuerpo.

Hay otro texto de Deleuze ${ }^{8}$ que reúne unas sesiones impartidas en 1981en las que el filósofo habla de pintura partiendo de la idea de que el acto de pintar no consiste en una fórmula aplicada sino que cada pintor sigue su propio método. Es llamativo que los primeros pintores que cita el filósofo, Cézanne, Paul Klee o Van Gogh hacen referencia a una experiencia de tipo cósmico que tiene que ver en gran medida con el comienzo del mundo y con una cierta mirada inocente y germinal. Seguidamente Deleuze destaca una temporalidad específica de la pintura que nos remite a una síntesis de tres momentos por los que ineludiblemente debe pasar el pintor. En primer lugar, la catástrofe o el abismo, luego el borrado como condición para que surja finalmente el hecho pictórico o la presencia.

La noción central que propone el filósofo francés en su caracterización de la pintura es la de diagrama. El diagrama son las marcas libres y borraduras que Bacon aplica en el interior de la imagen pintada para destruir la figuración naciente y alejar cualquier predisposición a aceptar lo ya dado, lo ya usado y gastado. Es introducir el azar, el accidente. El pintor hace marcas manuales al azar, trazos irracionales e involuntarios libres. Trazos asignificantes, de sensación como si la mano adquiriera independencia. Marcas manuales casi ciegas que constituyen la intrusión de un mundo no visual. Es el derrumbe de las coordenadas visuales. El diagrama entonces se sitúa en un momento pre-pictórico que Deleuze llama catástrofe. La catástrofe es lo que está siempre presente en los cuadros, pero no se refiere al tema, como es el caso del cuadro La tempestad de Giorgione, o como lo son los cuadros de Turner de tempestades en el mar, de diluvios, donde el desequilibrio se extiende por todo el cuadro. No. Es otra catástrofe más secreta que está latente en la tela. Es una catástrofe que, como afirma Deleuze, es pre-pictórica y tiene que ver con un caos, con el abismo que debe atravesar el pintor antes de ponerse a pintar. Esta catástrofe representa un gran peligro porque puede arruinar el cuadro asediándolo y en consecuencia el pintor deberá estar alerta, al acecho para controlar el caos-germen, que por otra parte es la verdadera matriz del cuadro. Ahora bien, según insiste Deleuze, la tela no es una superficie blanca, sino que, está atestada de clichés aunque no se

8 Deleuze, G., Pintura, El concepto de diagrama, Buenos Aires, Cactus, 2007. 
puedan ver. Por tanto, el trabajo del pintor consiste en destruirlos. El pintor debe atravesar por un momento en el cual no ve nada. Es como un hundimiento de las coordenadas visuales, que remueven todos los lugares comunes demasiado repetidos y en general todo aquello que pesa sobre el pintor en forma de ideas recibidas o sedimentos culturales ya gastados. Esta operación que recibe el nombre de catástrofe es fundamentalmente la lucha contra el cliché. Los datos pre-pictóricos son, en el sentido más amplio de la palabra, el mundo de los clichés o el mundo de los fantasmas, o de la fantasía, o de la imaginería, dice Deleuze. Es todo lo que el pintor tiene que suprimir antes de comenzar el acto de pintar, porque si permanece allí está perdido. Y es que vivimos en un mundo de clichés que están sobre la tela antes de que el pintor comience. Como ya se ha dicho aquí son tanto las imágenes desgastadas como los presupuestos y la mera intención pictórica figurativa del que se dispone a pintar. Pero la operación se complica porque como sostiene el filósofo: "Lo que hay de catastrófico es que apenas un pintor ha encontrado algo, se vuelve un cliché. Y hoy en día a toda velocidad. Existe una producción, una reproducción al infinito del cliché que hace que el consumo sea extremadamente rápido. ¡Lucha contra el cliché! Ese es, creo el grito de guerra del pintor." 9 De modo que el diagrama, que pertenece al orden del azar, es la zona de limpieza que hace catástrofe sobre el cuadro e instaura la posibilidad de lo que va a salir de la tela. Pero si el pintor no pasa por el caos-catástrofe permanece esclavo de los clichés. En la pintura, dice Deleuze, hay peligros por todas partes. Está por una parte el peligro de que el caos arruine el cuadro y por otra que sean los clichés los que se cuelen en la tela.

Por tanto la función del diagrama es borrar y suprimir los clichés. Es borrar narraciones y figuraciones porque la misión de la pintura no es pintar cosas visibles, sino hacer visible lo invisible, como decía Paul Klee. No es pintar formas sino fuerzas. Es pintar la relación del cuerpo visible con la fuerza invisible. Si el pintor logra que un cuerpo que muere vuelva visible la fuerza de la muerte, quizá la muerte llegue a ser en ese momento, para nosotros, para el cuerpo representado, una verdadera amiga. La pintura nos proporciona así una especie de inmenso consuelo vital. ${ }^{10}$ Su tarea consiste en captar las potencias y transformarlas. Así, en la medida en que se vuelve visible, esa fuerza enemiga se transforma en amiga, en algo distinto de la muerte.

Ahora bien, en ese abismo en el que se hace presente el diagrama se da cierto antagonismo entre la mano y el ojo, un antagonismo que opera en tanto que una tensión entre ambos, el diagrama es fundamentalmente manual. Se podría decir que el diagrama es una mano ciega desencadenada que se libera de su subordinación a las coordenadas visuales, de tal manera que el ojo no hace más que seguir a la mano arrastrada por una voluntad extraña, movida por una potencia exterior que el artista siente en su interior. En relación a lo que está llamado a salir del cuadro, la línea pertenece al ámbito de lo visual y en cambio el trazo es exclusivamente manual. El 9 Ibídem, p. 56. 10 Ibídem, p. 81. 
trazo/mancha es la unidad pictórica manual que va a implicar el hundimiento visual, de tal manera que emerge algo nuevo que Deleuze llama "el tercer ojo". Es así como el diagrama deshace la semejanza en provecho de una semejanza más profunda y vacía la tela de representaciones para hacer surgir la presencia. La representación es el antes de pintar, la presencia es lo que sale del diagrama. Ha sido preciso pasar por un caos o un abismo del diagrama manual para producir el hecho pictórico o un "tercer ojo" que instaura el orden propio del abismo.

Es relevante aquí destacar que Deleuze llega a la conclusión de que la pintura es fundamentalmente analógica. Hace la distinción entre lo analógico y lo digital y define ambas nociones por oposición. El punto de partida es la tensión entre la mano y el ojo. El lenguaje analógico es aquel en el que la mano no está sometida al ojo. Pero el digital es un lenguaje eminentemente óptico en el que la mano queda reducida al dedo, al dedo del ordenador. Como lenguaje articulado el digital está constituido por unidades significativas determinables por una sucesión de elecciones binarias. En cambio el analógico no está articulado, sino que está hecho de elementos no lingüísticos que son movimientos o kinesis. El analógico es el lenguaje de las emociones que se expresan con elementos sonoros inarticulados como las respiraciones o los gritos. Así pues, lo analógico no se refiere al lenguaje convencional de la armonía que tiene articulaciones, sino al lenguaje natural de la melodía. Un lenguaje natural que puede llegar a ser bestial, animal. Porque el origen del lenguaje es la pasión. Estamos ante pathos por oposición a logos. Logos es el código, esto es el lenguaje digital, en contraste con la voz melódica que es modulación, porque modular es modificar la frecuencia o la amplitud de la onda portadora en función de la señal y, en consecuencia, pintar es modular la luz y el color en función del motivo o el modelo. Entonces, la gran analogía estética ya no se define por la similitud, sino por la modulación, de tal modo que pintar es producir semejanza por medios no semejantes y la matriz de la pintura es analógica porque es un lenguaje natural, animal.

Este es según Deleuze el hecho pictórico que, como hemos visto, está fundamentalmente determinado por una lucha a muerte contra el fantasma del cliché que lo invade todo. Este es el mayor peligro del acto de pintar, en el que insiste el filósofo, a saber: que los clichés se cuelen en la tela. Podríamos decir entonces que el pintor ha de contar con muchas fuerzas para salir airoso de la lucha sin cuartel contra esos clichés que asedian su pintura por una reproducción al infinito, a toda velocidad. Por tanto, el destino del pintor es un destino trágico.

Así traza Ramón Gaya en su "Dibujo sentimental de Rosales" los rasgos de esa lucha dramática del creador: «He dicho que el fuego te ha matado. No morías de "tisis", sino de ti, de ti mismo matándote, porque eras esa fuerza suicida de artista, esa gran fuerza que envenena, que rompe.»11

11 Gaya, R., Obra completa, Valencia, Pre-Textos, p. 691. 
¿Será la lucha contra el cliché esa fuerza destructora? ¿No será que la lucha contra el cliché es precisamente el cliché? La creatividad está presa de la fobia del cliché. Es como si ya hubiera sido atrapada por el fantasma, como si ya fuera tarde para impedir que toda una legión de clichés capture a la belleza. ¿No es ella acaso su rehén? Gaya en 1935 alude también a este peligro: « ¿Para qué buscar ser nuevo, si somos nuevos con sólo abandonarnos al vivir? No huyamos, no nos inventemos fantasmas nosotros mismos, ya que podríamos crearlos de tal modo que, sin existir, terminarían por dañarnos.»12

¿Estaría de acuerdo Ramón Gaya con los que dan por concluida a la pintura? Más bien al contrario nos dice: «Y no creo que la pintura esté terminada, ya que esto sería suponer que el arte es un problema, un problema al que se encontró la solución».13

$\mathrm{Y}$ ciertamente la pintura sigue siendo un asunto que nos inquieta. Si retomamos esa tensión que propone Deleuze entre lo natural y lo convencional, entre el pathos y el logos, entre lo animal y lo racional, entre la melodía y la articulación, entre lo analógico y lo digital, podríamos decir, entonces que el hecho pictórico tiene dos vertientes: una analógica y corporal o carnal que se expresa con trazos y otra digital o como dice Leonardo da Vinci, "mental" que se hace patente en el dibujo de línea. Curiosamente también podemos encontrar algunas afirmaciones de Gaya en las que califican el acto creador de carnal por contraposición a lo mental. ${ }^{14}$ Por consiguiente las artes plásticas tienen una doble cara, la del trazo pictórico que es carnal y corporal, atravesado por el azar y la del dibujo de línea que es básicamente racional, proyectado de antemano. Desde la perspectiva filosófica de Deleuze la modulación es anterior a la articulación y el germen o la posibilidad de la pintura tiene que ver con algo no programado, no articulado, no formulado, de carácter analógico que opera en relación a un abismo, en relación al borrar, al vaciar, a traspasar lo figurativo para hacer visible lo invisible, para transformar las potencias enemigas en potencias amigas. Se trata, por tanto, de romper con la representación para hacer surgir la presencia con el trazo de una mano que ya no obedece las órdenes del ojo, sino que obedece una fuerza exterior que abre un "tercer ojo". Con esta afirmación se diría que Deleuze está caracterizando la pintura como una operación cercana a lo mágico, a lo místico que trasciende el plano inmediato de la experiencia y nos recuerda el soneto "De pintor a pintor" que escribe Ramón Gaya en 1978:

«pintar es tantear -atardeciendo-

la orilla de un abismo con tu mano,

12 Ídem.

13 Ib., p. 707.

14 Gaya expresa en más de una ocasión su discrepancia con el aforismo atribuido a Leonardo da Vinci que afirma que la pintura es algo mental. Por el contrario el pintor murciano dice que la pintura es carnal, Obra completa, Valencia, Pre-Textos, pp. 104,114, 211-213, 861 y 868. 
temeroso adentrarte en lo lejano, temerario tocar lo que vas viendo.»15

Hay algo irracional y misterioso que nos sugiere un devenir más profundo donde la figura desaparece y entra en el reino borroso de lo indeterminado. Deleuze cita textualmente al entrevistador de Bacon que dice: "En todas partes el reino de lo borroso y de lo indeterminado, la acción de un fondo que atrae la forma, un tratamiento malerisch". Malerisch que es para Wölfflin lo pictórico en oposición a lo lineal. Malerisch, pictórico, de maler, pintor en alemán, que viene del verbo malen, de manchar, de mácula que es de donde deriva la palabra "mal". 16

El concepto del hecho pictórico que describe Deleuze es el de una presencia de figuras indomables por su insistencia. Un ejemplo de esta insistencia es la obra de Richard Hambleton (Vancouver 1954) que ejecutó entre 1981 y 1986 en Nueva York su serie más característica: "Night life" (vida nocturna). Night life se compone de cuatrocientas cincuenta sombras humanas de tamaño natural que tituló "shadow man", hombre sombra, pintadas de forma gestual con brocha y pintura negra. Eran sombras que acechaban en las paredes de las esquinas, de los aparcamientos y de los callejones solitarios de la ciudad. Sombras que jugaban con el estado de paranoia social causado por la alta criminalidad callejera de la época. Hambleton propagó sus hombres sombra como fantasmas inquietantes a lo largo de 1984 en doce grandes ciudades europeas, Madrid entre ellas. ${ }^{17}$

¿Será acaso que la pintura se ha retirado al reino de las sombras para conjurar el miedo? ¿Han sido estas sombras la expresión de un final de la modulación analógica como lenguaje característico de la pintura y de la expresión de las emociones?

Ante la evidencia del paradigma del dominio digital que no parece necesitar de la pintura, tal vez quepa aún poner en tela de juicio las afirmaciones que pretenden pronosticar su liquidación definitiva desde esa lógica mercantil de la obsolescencia que se nos quiere imponer como rectora de nuestra experiencia, como si estuviéramos viviendo en dos mundos a la vez, o como si uno de ellos estuviera disolviéndose en el otro. No. No se inquieten: el mundo analógico no ha desaparecido. Es más bien la condición de posibilidad del digital y no al revés. Y en cuanto a la supuesta muerte de la pintura basta con darse una vuelta por cualquier ciudad y mirar alrededor para reparar en ese impulso diseminado por doquier, en las vallas, en las fachadas, en las puertas. Una fuerza que alcanza todos los espacios urbanos donde apenas queda una superficie por pintar. Escrituras anónimas de grandes tra-

\footnotetext{
15 Ibídem, p. 637.

16 G. Deleuze, Francis Bacon, Lógica de la sensación, Madrid, Arena libros, 2009, p. 37.

17 Las referencias a Hambleton están extraídas del documento electrónico disponible en: http://urbanario.es/archives/389
} 
zos que son pacientemente borradas por los servicios de limpieza municipales, superficies limpiadas sin cesar y que una multitud de manos vuelve a manchar obstinadamente, eternizando así el mismo movimiento circular: pintar, borrar, pintar, como si la pintura insistiese, como si quisiera volver, como si quisiera despertar. 